\title{
Functional Evidence for a Second Tumor Suppressor Gene on Human Chromosome 17
}

\author{
PENGCHIN CHEN, ${ }^{1} \dagger$ NELSON ELLMORE, ${ }^{2}$ AND BERNARD E. WEISSMAN ${ }^{1 *}$ \\ Lineberger Comprehensive Cancer Center and Department of Pathology, University of North Carolina, \\ Chapel Hill, North Carolina 27599, ${ }^{1}$ and Laboratory of Cellular and Molecular Biology, \\ National Cancer Institute, Bethesda, Maryland 20892 2
}

Received 8 July 1993/Returned for modification 16 August 1993/Accepted 12 October 1993

\begin{abstract}
The development and progression of human tumors often involves inactivation of tumor suppressor gene function. Observations that specific chromosome deletions correlate with distinct groups of cancer suggest that some types of tumors may share common defective tumor suppressor genes. In support of this notion, our initial studies showed that four human carcinoma cell lines belong to the same complementation group for tumorigenic potential. In this investigation, we have extended these studies to six human soft tissue sarcoma cell lines. Our data showed that hybrid cells between a peripheral neuroepithelioma (PNET) cell line and normal human fibroblasts or HeLa cells were nontumorigenic. However, hybrid cells between the PNET cell line and five other soft tissue sarcoma cell lines remained highly tumorigenic, suggesting at least one common genetic defect in the control of tumorigenic potential in these cells. To determine the location of this common tumor suppressor gene, we examined biochemical and molecular polymorphic markers in matched pairs of tumorigenic and nontumorigenic hybrid cells between the PNET cell line and a normal human fibroblast. The data showed that loss of the fibroblast-derived chromosome 17 correlated with the conversion from nontumorigenic to tumorigenic cells. Transfer of two different chromosome 17s containing a mutant form of the p53 gene into the PNET cell line caused suppression of tumorigenic potential, implying the presence of a second tumor suppressor gene on chromosome 17.
\end{abstract}

The development of human tumors progresses in a multistep fashion. In searching for the genetic basis of tumorigenicity, molecular studies have focused on two groups of genes involved in the process of neoplastic transformation. One group, termed oncogenes, act dominantly to transform normal cells into tumorigenic cells, leading to the assumption that tumorigenicity behaves as a dominant genetic trait (4). However, somatic cell genetic studies showed that tumorigenic potential could be suppressed upon addition of normal genetic information (44). Together with the evidence from familial cancer genetics and cancer cytogenetics, several researchers proposed the existence of tumor suppressor genes which must be lost or inactivated during tumor formation $(9,21)$.

Characterization of somatic cell hybrids has provided valuable information on the localization of these tumor suppressor genes. Somatic cell hybrids between human cell lines and normal human fibroblasts were initially suppressed for tumorigenic potential $(2,35)$. After continuous passage of the nontumorigenic hybrid cells in culture, rare tumorigenic variants which contained a reduced chromosomal number arose $(2,35)$. Cytogenetic analysis revealed preferential loss of certain chromosomes $(2,37)$, and restriction fragment length polymorphism (RFLP) differences confirmed their origin from the normal parent (34).

Because different fibroblast chromosomes were lost in different sets of human tumor $\times$ normal hybrid cells upon tumorigenic reexpression, the possibility of multiple tumor

\footnotetext{
* Corresponding author. Mailing address: Lineberger Comprehensive Cancer Ctr., CB 7295, University of North Carolina at Chapel Hill, Chapel Hill, NC 27599. Phone: (919) 966-7533. Fax: (919) 966-3015.

$\dagger$ Present address: Brain Tumor Research Center, University of California Medical School, San Francisco, CA 94143.
}

suppressor genes arose. We initially tested this hypothesis by carrying out a complementation analysis of adult human cancer cell lines. Our studies showed that four human carcinoma cell lines belonged to the same complementation group, as hybrids among them remained tumorigenic (46). However, hybrid cells between a cervical carcinoma and either a fibrosarcoma or a melanoma cell line were suppressed for tumorigenic potential (46). These data suggested that tumor cells of the same developmental lineage may share a common genetic defect in the regulation of tumor growth.

In this investigation, we have expanded these early studies to include six different soft tissue sarcoma cell lines. Fusion of a common peripheral neuroepithelioma (PNET) cell line to three fibrosarcoma cell lines, one embryonal rhabdomyosarcoma cell line, and one other PNET cell line resulted in highly tumorigenic hybrid cell lines. These data suggest that at least one common genetic defect in the control of tumorigenic potential exists for these soft tissue sarcoma cell lines. By characterizing matched sets of nontumorigenic PNET $\times$ normal human fibroblast hybrids and their tumorigenic segregants, we have mapped one functional tumor suppressor gene to chromosome 17. However, a functional analysis using monochromosome transfer appears to eliminate the p53 gene as the operative tumor suppressor gene.

\section{MATERIALS AND METHODS}

Cell lines. Table 1 lists the cell lines used in this study. The Lesch-Nyhan human fibroblast strain, GM2291, was used as the normal parental cell. Soft tissue sarcoma cell lines included a thymidine kinase-deficient $\left(\mathrm{TK}^{-}\right)$clone of the PNET cell line A673 designated A673 BrdU (14); three clonally derived hypoxanthine guanine phosphoribosyltransferase-deficient $\left(\right.$ HPRT $^{-}$) fibrosarcoma cell lines, HT1080 
TABLE 1. In vivo growth characteristics of parental cell lines

\begin{tabular}{lllc}
\hline \multicolumn{1}{c}{ Cell line } & Tumor type & $\begin{array}{c}\text { Modal } \\
\text { chromo- } \\
\text { some } \\
\text { no. }\end{array}$ & $\begin{array}{c}\text { Tumorigenicity } \\
\text { (no. of sites } \\
\text { positive/no. } \\
\text { inoculated s.c.) }\end{array}$ \\
\hline A673 BrdU & PNET & 63,67 & $6 / 6$ \\
D980R & $\begin{array}{l}\text { Cervical carci- } \\
\text { noma }\end{array}$ & 63 & $10 / 10$ \\
HS913T 6TG & $\begin{array}{l}\text { Fibrosarcoma } \\
\text { HT1080 6TG C5 }\end{array}$ & $\begin{array}{l}\text { Fibrosarcoma } \\
\text { HuT14 6TG }{ }^{\circ} \text { R (8387) }\end{array}$ & $\begin{array}{l}\text { Fibrosarcoma } \\
\text { Embryonal rhab- }\end{array}$ \\
RD & 46 & 46 & $12 / 4$ \\
SK-N-MC & domyosarcoma & 46 & $6 / 8$ \\
\hline & PNET & 46 & $6 / 6$ \\
\hline
\end{tabular}

(29), HuT14/8387 $(20,25)$, and HS913T (American Type Culture Collection, Bethesda, Md.); an embryonal rhabdomyosarcoma cell line, RD (24); and a second PNET cell line, SK-N-MC (3). The ouabain-resistant, HPRT ${ }^{-}$HeLa cell derivative $\mathrm{D} 98 \mathrm{oR}$ was used as a fusion partner of unrelated developmental origin (45). We also included several cell lines as controls for p53 or retinoblastoma protein (RB) expression, including a neuroblastoma cell line, NGP9ATr1 (5), with an apparently normal p53 gene, and A388 and SW620, which possess mutant $\mathrm{p} 53$ proteins $(1,14)$. Cell lines were maintained in RPMI 1640 plus $10 \%$ fetal calf serum (growth medium). All cell lines were tested for Mycoplasma contamination (36).

Cell fusions. Cell hybrids were isolated by using polyethylene glycol as previously described (45). For the A673 BrdU $\times$ fibrosarcoma fusions, hybrids cells were selected for growth in hypoxanthine-aminopterin-thymidine (HAT) selective medium. We isolated the other hybrid cell lines by growth in HAT selective medium containing $600 \mu \mathrm{g}$ of G418 per ml by using a neomycin-resistant A673 BrdU cell line as the common parent. At least three independent clones from each experiment were selected for further characterization.

Characterization of hybrid cells. All hybrid cells were examined for chromosome content and for either isozyme profile or presence of polymorphic molecular markers. Chromosomes were prepared by the method of Nelson-Rees et al. (26), and at least 20 metaphase spreads were examined for each clone. Glucose oxidase 1 (GLO-1) isozyme analysis was performed by Ward Peterson of the Childrens Hospital of Detroit, using cellulose acetate electrophoresis. RFLP markers were detected by the Southern blotting technique as described by Scrable et al. (33).

Tumorigenicity assay. The tumorigenic potential of the parental and hybrid cell lines was determined by subcutaneous (s.c.) injection of $10^{7}$ cells $\left(3 \times 10^{7}\right.$ cells for NGP9ATr1) into nude mice. Mice were examined weekly for tumor formation for up to 6 months. Tumors formed after inoculation of hybrid cells were reestablished into tissue culture and analyzed for chromosomal content and RFLP markers.

Expression of p53 and RB genes. Expression of p53 and $r b-1$ mRNAs was determined by standard Northern (RNA) blot analysis as previously described (28), using a 1.8-kb BamHI fragment of p53 cDNA and a 3.8-kb EcoRI fragment of RB cDNA, respectively, as probes. Expression of the RB protein was determined by Western blot (immunoblot) analysis as described by Futreal and Barrett (12), with a slight modification. Samples $\left(2 \times 10^{6}\right.$ cells) were lysed with sample buffer, passed through 19- and 25-gauge needles, boiled, separated by sodium dodecyl sulfate-polyacrylamide gel electrophoresis (SDS-PAGE), and transferred to an Immobilon-P membrane (Millipore) by electroblotting. The membrane was pretreated with a blocking solution, incubated with anti-human RB antibody PMG3-245 (PharMingen), and washed. After incubation with secondary alkaline phosphatase-conjugated anti-mouse immunoglobulin $\mathrm{G}$, the bands were visualized by adding nitroblue tetrazolium and 5-bromo-4-chloro-3-indolyl phosphate (Oncogene Science). p53 was immunoprecipitated with monoclonal antibody Ab-1 as specified by the manufacturer (Oncogene Science). Brieffy, total cellular proteins labelled with $\left.{ }^{35} \mathrm{~S}\right]$ methionine were incubated with monoclonal antibody $\mathrm{Ab}-1$ at $4^{\circ} \mathrm{C}$. Immune complexes were isolated by precipitation with Pansorbin (Calbiochem) and separated by SDS-PAGE. The gel was treated with $\mathrm{En}^{3} \mathrm{Hance}$ (Du Pont) and dried, and protein bands were visualized by autofluorography.

Dinucleotide repeat polymorphisms. Dinucleotide $(\mathrm{CA})_{n}$ repeat polymorphic regions were amplified as described by Weber and May (43) with ${ }^{32} \mathrm{P}$-end-labelled primers. PCR products were separated by a DNA sequencing gel, and bands were visualized by autoradiography. Sequences of primers used in PCR were 5'-GGAAGAATCAAATAGA CAAT-3' and ' 5'-GCTGGCCATATATATATTTAAACC-3' for the Mfd15 locus (42), 5'-ACAGAGTGAGACCGTG TAAC-3' and ' '-AGAGAAGCATCTCACTTAGT-3' for the Mfd47 locus (40), and 5'-TAGCTGGTGCATAAGCT CAC-3' and 5'-GTTAGTGGAAGAGCAGAGC-3' for the Mfd69 locus (41).

VNTR region amplification. The VNTR region of the pYNZ22 locus was amplified as described by Horn et al. (18). PCR products were fractionated on a $2 \%$ agarose gel and visualized by ethidium bromide staining. The sequences of the primers were 5'-CGAAGAGTGAAGTGCACAGG-3' and 5'-CACAGTCTTTATTCATCAGCG-3'.

p53SR amplification. The p53SR marker, which recognizes an $(\mathrm{AAAAT})_{n}$ simple repeat in the first intron of the p53 gene, was assayed by a PCR reaction similar to that used for the Mfd dinucleotide repeats (13). The sequences of the primers were 5'-GTGGCACATGCTTGTAGTCC-3' and 5'CAGCTCCTTTAATGGCAGGC-3', corresponding to nucleotides 8848 to 8867 and 9037 to 9056 of the p53 gene.

Sequencing of p53 mRNA. The sequence of the p53 mRNA in cell lines was determined by asymmetric sequencing of reverse transcription-PCR products as described by Nigro et al. (27). After synthesis of CDNA, a 1.2-kb PCR product was isolated after amplification with the following primers: 5'GGCGGGGATCCATGGAGGAGCCGCAGTCAGAT-3' and 5'-GGCGGGAATTCAGTCTGAGTCAGGCCCTTCT$3^{\prime}$. The primer for sequencing was 5'-CTGAGGTTGGCTC TGACTG-3'.

Microcell hybridization. Microcell hybridization was carried out as previously described (30). At least two independent colonies were isolated for cytogenetic and molecular characterization. All microcell hybrids were screened by molecular and cytogenetic methods for the presence of mouse genetic material after transfer; none was detected.

\section{RESULTS}

A673 BrdU $\times$ fibroblast hybrid cells. We initially fused the A673 BrdU cells to the normal fibroblast cell GM2291 to demonstrate the recessive nature of tumorigenicity for these cells. Table 2 summarizes the characteristics of these hybrid cells. Hybrid cell identity was confirmed by both modal chromosome number and GLO-1 isozyme expression. Of the four hybrid cell lines, two (HHy5 P1 and HHy5 P4) retained 
TABLE 2. In vivo growth characteristics of PNET $\times$ fibroblast hybrids

\begin{tabular}{|c|c|c|c|c|}
\hline Cell line ${ }^{a}$ & Parental cell line & $\begin{array}{c}\text { Modal } \\
\text { chromosomal } \\
\text { no. } .^{b}\end{array}$ & $\begin{array}{l}\text { GLO-1 isoform(s) } \\
\text { expressed }^{c}\end{array}$ & $\begin{array}{l}\text { Tumorigenicity (no. } \\
\text { of sites positive/no. } \\
\text { injected s.c.) }\end{array}$ \\
\hline A673 BrdU & PNET & $63,67(61-67)$ & 2 & $6 / 6$ \\
\hline GM2291 & Lesch-Nyhan fibroblast & 46 & 1 & $0 / 10$ \\
\hline \multicolumn{5}{|l|}{ HHy 5} \\
\hline $\begin{array}{l}\text { P1 } \\
\text { P1T1 }\end{array}$ & A673 BrdU $\times$ GM2291 & $104(92-108)$ & $1-2$ & $1 / 5$ \\
\hline P2 & & $77,78(73-80)$ & 1 & $\begin{array}{l}4 / 4 \\
6 / 6\end{array}$ \\
\hline $\begin{array}{l}\text { P2T1 } \\
\text { P3 } \\
\text { P3T1 }\end{array}$ & & $\begin{array}{l}84(77-85) \\
80,106(77-109) \\
83(80-86)\end{array}$ & $1-2$ & $8 / 11$ \\
\hline $\mathrm{P} 4$ & & $105(87-109)$ & $1-2$ & $0 / 3,1 / 4$ \\
\hline P4T1 & & $92(88-95)$ & & $4 / 4$ \\
\hline
\end{tabular}

a $\mathrm{T} 1$ indicates derivation from a tumor formed by the preceding cell line.

$b$ Numbers in parentheses represents the ranges of chromosome numbers for the cell lines.

$c$ Determined by cellulose acetate gel electrophoresis.

most of chromosomes from the parental cell lines. When assayed for tumorigenic potential in nude mice, HHy5 P4 was completely suppressed for tumorigenicity in one s.c. inoculation and formed only one tumor in four sites in a second experiment. Similarly, the HHy5 P1 cell line formed only one tumor in five sites. When these tumors were reestablished into culture, their chromosome contents were reduced by $30 \%$, suggesting a loss of the tumor suppressor information from the cells. Inoculation of the tumorigenic segregant produced rapidly arising tumors in all sites, consistent with this interpretation. Although the HHy5 P3 cell line formed tumors in the majority of sites, a bimodal chromosome content was present. Cytogenetic analyses of the tumor reconstituted cell lines revealed only the lower modal chromosome number in the tumor cell lines. The HHy5 P2 cell line had already lost a significant number of parental chromosomes before inoculation, presumably contributing to its highly tumorigenic potential. These data indicated that tumorigenicity behaved as a recessive genetic trait in A673 BrdU cells, validating their use as the common parental cell line for complementation analysis.

Sarcoma $\times$ sarcoma hybrid cells. Our previous studies suggested that tumors derived from the same developmental lineage share a common defective tumor suppressor gene (46). Therefore, if soft tissue sarcomas contain defects in different tumor suppressor genes, hybrid cells between them should display a nontumorigenic phenotype due to the recessive genetic nature of tumorigenicity. However, if soft tissue sarcomas share at least one defective tumor suppressor gene, all hybrid cells should remain tumorigenic.

To distinguish between these possibilities, we hybridized the A673 BrdU cell line with three fibrosarcoma cell lines (HT1080 6TG C5, HuT14 6TG, and HS913T 6TG), an embryonal rhabdomyosarcoma cell line (RD), and a second PNET cell line (SK-N-MC), using the HAT or HAT-neomycin selection system. Table 3 shows that each set of hybrid cell lines possesses a modal chromosomal content compatible with the total chromosome complement of both parental cells. To confirm the presence of chromosomes from both parents, RFLP probes for H-ras, located on short arm of chromosome 11, and pYNZ2, on chromosome 1p, were chosen for their high degree of polymorphism. The $\mathrm{HHy} 7$ cells possessed a 4.2-kb band from A673 BrdU and a 3.7-kb band from the HT1080 parent when hybridized with the pYNZ2 probe (Fig. 1A). When the same Southern blot was assayed with the H-ras probe, all hybrid cells retained the
A673-specific 2.9-kb band and the HT1080 2.2- and 1.7-kb bands except HHy7 P7 (Fig. 1B). This cell line had lost one molecular marker from the HT1080 parent. Thus, the hybrid cell lines showed evidence of a chromosome contribution from both parental cells. In the case of the HHy56 cell lines, total cellular DNA was digested with the TaqI enzyme. Hybridization with the pYNZ2 probe gave a $6.1-\mathrm{kb}$ band for A673 BrdU, while HuT14 gave 6.1- and 5.7-kb bands in a ratio of 1:1 (Fig. 2A). The presence of the $5.7-\mathrm{kb}$ band in the hybrid cells indicates the genetic contribution from HuT14 cells, while the increased ratio of the $6.1-$ to $5.7-\mathrm{kb}$ bands

TABLE 3. In vivo growth characteristics of sarcoma $\times$ sarcoma hybrid cells

\begin{tabular}{|c|c|c|c|}
\hline $\begin{array}{l}\text { Cell } \\
\text { line }^{a}\end{array}$ & Parental cell lines & $\begin{array}{c}\text { Modal } \\
\text { chromosome } \\
\text { no. }^{b}\end{array}$ & $\begin{array}{c}\text { Tumorigenicity } \\
\text { (no. of animals } \\
\text { positive/no. } \\
\text { inoculated) }\end{array}$ \\
\hline \multicolumn{4}{|l|}{ HНy 7} \\
\hline P6 & \multirow{4}{*}{$\begin{array}{l}\text { A673 BudR, HT1080 } \\
\text { 6TG C5 }\end{array}$} & $110(80-125)$ & \multirow[t]{2}{*}{$8 / 8$} \\
\hline P6T & & $111(88-114)$ & \\
\hline P7B & & $98(82-110)$ & $8 / 8$ \\
\hline P8A & & $130(126-187)$ & $6 / 6$ \\
\hline \multicolumn{4}{|l|}{ HНy56 } \\
\hline P1 & \multirow{4}{*}{$\begin{array}{l}\text { A673 BudR, HuT14 } \\
\text { 6TG }\end{array}$} & $92(79-104)$ & \multirow[t]{2}{*}{$4 / 5$} \\
\hline P1T & & $96(88-110)$ & \\
\hline P4 & & $101(90-105)$ & $4 / 4$ \\
\hline \multirow{2}{*}{\multicolumn{4}{|c|}{ HHy58 }} \\
\hline & & & \\
\hline P1 & \multirow{4}{*}{$\begin{array}{l}\text { A673 BudR, HS913T } \\
\text { 6TG }\end{array}$} & $129(105-141)$ & \multirow[t]{2}{*}{$6 / 6$} \\
\hline P1T & & $130(86-146)$ & \\
\hline P3 & & $144(121-153)$ & $6 / 6$ \\
\hline P5 & & $122(107-138)$ & $5 / 6$ \\
\hline \multicolumn{4}{|l|}{ HHy69 } \\
\hline P4A & \multirow[t]{4}{*}{ A673 BudR, RD } & $107(91-110)$ & \multirow[t]{2}{*}{$6 / 6$} \\
\hline P4AT & & $100(96-112)$ & \\
\hline P6B & & $96(88-104)$ & $6 / 6$ \\
\hline P7A & & $105(101-114)$ & $6 / 6$ \\
\hline \multicolumn{4}{|l|}{ HНy 73} \\
\hline P1 & \multirow{4}{*}{$\begin{array}{l}\text { A673 BudR, SK-N- } \\
\text { MC }\end{array}$} & $88(78-91)$ & $6 / 6$ \\
\hline P1T & & $83(78-86)$ & \\
\hline P2 & & 98 (88-104) & $6 / 6$ \\
\hline P3 & & $100(92-103)$ & $6 / 6$ \\
\hline
\end{tabular}

${ }^{a} \mathrm{~T}$ indicates derivation from a tumor formed by the preceding cell line.

${ }^{b}$ Numbers in parentheses represent the ranges of chromosome numbers observed in the cells. 


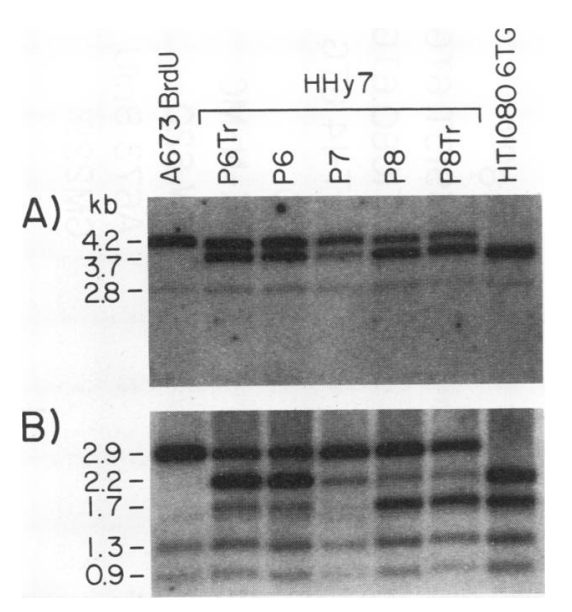

FIG. 1. RFLP analysis of HHy7 (A673 BrdU $\times$ HT1080) hybrid cells. Ten micrograms of total cellular DNA from $\mathrm{HHy} 7$ hybrid and tumor-reconstituted cell lines was isolated, digested with PstI, and transferred to nitrocellulose filters. Filters were hybridized with either ${ }^{32} \mathrm{P}$-labelled pYNZ2 probe (A) or ${ }^{32} \mathrm{P}$-labelled human $\mathrm{H}$-ras probe (B) as described by Scrable et al. (33). The bands were then visualized by autoradiographic techniques.

indicates the presence of the genetic material from A673 cells. A similar approach was also applied to the HHy58 (A673 $\times$ HS913T), HHy69 (A673 × RD), and HHy73 (A673 $\times$ SK-N-MC) hybrid cell lines; again, all hybrid cell lines displayed RFLPs characteristic of both parental cell lines (data not shown).

All five sets of hybrid cell lines formed large progressive tumors upon s.c. inoculation into nude mice (Table 3). Therefore, all soft tissue sarcoma cell lines shared at least

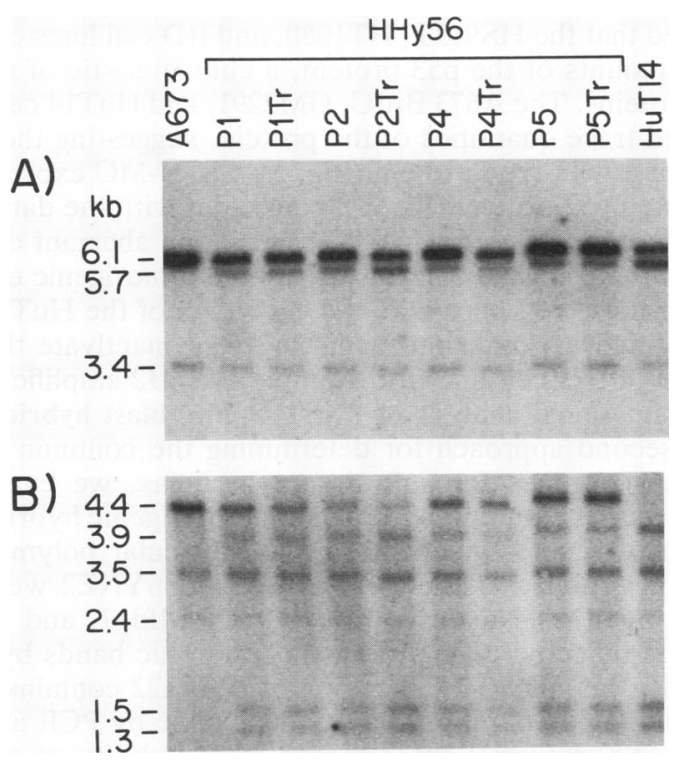

FIG. 2. RFLP analysis of HHy56 (A673BrdU $\times$ HuT14 6TG) hybrid cells. Ten micrograms of total cellular DNA from HHy56 hybrid and tumor-reconstituted cell lines was isolated, digested with TaqI, and transferred to nitrocellulose filters. Filters were hybridized with either ${ }^{32} \mathrm{P}$-labelled $\mathrm{pYNZ2}$ probe $(\mathrm{A})$ or ${ }^{32} \mathrm{P}$-labelled human $\mathrm{H}$-ras probe (B) as described by Scrable et al. (33). The bands were then visualized by autoradiographic techniques.
TABLE 4. In vitro and in vivo characteristics of A673 $\times$ HeLa hybrids

\begin{tabular}{|c|c|c|c|c|}
\hline \multirow{2}{*}{ Cell line $e^{a}$} & \multicolumn{2}{|c|}{$\begin{array}{c}\text { RFLP marker } \\
\text { band(s) }\end{array}$} & \multirow{2}{*}{$\begin{array}{c}\text { Modal } \\
\text { chromosome } \\
\text { no. }^{c}\end{array}$} & \multirow{2}{*}{$\begin{array}{c}\text { Tumorigenicity } \\
\text { (no. of sites } \\
\text { positive/no. } \\
\text { inoculated s.c. } \\
\text { in nude mice) }\end{array}$} \\
\hline & H-ras & pYNZ2 & & \\
\hline $\begin{array}{l}\text { A673 BrdU } \\
\text { D98oR } \\
\text { HHy78 }\end{array}$ & $\begin{array}{l}\mathrm{A} 1 \\
\mathrm{~A} 3\end{array}$ & $\begin{array}{l}\text { B1 } \\
\text { B2 }\end{array}$ & $\begin{array}{l}63,67 \\
61\end{array}$ & $\begin{array}{l}6 / 6 \\
6 / 6\end{array}$ \\
\hline $\begin{array}{l}\text { P1 } \\
\text { P2 } \\
\text { P2T } \\
\text { P3 }\end{array}$ & $\begin{array}{l}\text { A1-3 } \\
\text { A1-3 } \\
\text { A1-3 } \\
\text { A1-3 }\end{array}$ & $\begin{array}{l}\text { B1-2 } \\
\text { B1-2 } \\
\text { B1-2 } \\
\text { B1-2 }\end{array}$ & $\begin{array}{l}130(102-133) \\
108(97-112)\end{array}$ & $\begin{array}{l}0 / 6 \\
8 / 8\end{array}$ \\
\hline
\end{tabular}

${ }^{a} \mathrm{~T}$ indicates derivation from a tumor formed by the preceding cell line.

${ }^{b} \mathrm{Al}, 2.9 \mathrm{~kb}$; A3, $1.7 \mathrm{~kb}$; B1, $4.2 \mathrm{~kb}$; B2, $3.7 \mathrm{~kb}$; common bands are excluded for clarity. Bands were detected by Pst I digestion.

$c$ Numbers in parentheses represent the ranges of chromosome numbers for the cell lines.

one genetic alteration with the A673 BrdU cells leading to tumorigenic expression. Alternatively, growth in the animals might have selected for cells which lost a tumor suppressor gene from one of the parent cell lines. We established cell lines from representative tumors for each set of hybrid cell lines and characterized their chromosomal content and RFLP patterns (Table 3; Fig. 1 and 2). These data revealed no differences between the original hybrid cell lines and the tumors formed by them (compare with the A673 BrdU $\times$ fibroblast results; Table 2). Thus, the retention of tumorigenic potential in the hybrid cells appeared to result from a lack of complementation and not the loss of parental genetic information.

PNET $\times$ HeLa hybrid cells. Previous studies on tumorigenicity complementation groups indicated that the D98 HeLa cell line and HT1080 complement each other for tumorigenicity (46). To further confirm that tumor cells from different developmental lineages (carcinoma and sarcoma) have defects in different tumor suppressor genes, we hybridized A673 BrdUNeo with D98oR cells, using the HAT-plus-G418 selection system (Table 4). The hybrids were first screened by RFLP analyses using the $\mathrm{H}$-ras and $\mathrm{pYNZ2}$ markers with chromosomal locations of $11 \mathrm{p} 15.5$ and $1 \mathrm{p} 32$, respectively. Clone 1 (HHy78 P1), which retained both the pYNZ2 and H-ras markers and most of the chromosomes from the parental cell lines, showed complete suppression of tumorigenicity when inoculated into nude mice (Table 4). Clone 2 (HHy78 P2) retained the RFLP patterns of both pYNZ2 and H-ras markers but showed a chromosome number $20 \%$ less than that predicted for the combination of both parents. This hybrid was tumorigenic perhaps as a result of this low chromosome number (Table 4). In contrast, clone 3 (HHy 78 P3) demonstrated characteristics similar to those of clone 2 but was completely suppressed for tumorigenicity (Table 4). These data indicated that the A673 and D980R cell lines fall into different complementation groups for tumorigenicity, consistent with the earlier studies using the D980R and HT1080 cell lines (46).

Expressions of RB and p53 in parental and hybrid cells. We next determined whether a known tumor suppressor regulated tumorigenic potential in these cells. Individuals with hereditary defects in the RB gene possess a predisposition to retinoblastoma and several other mesenchymal tumors, including soft tissue sarcomas (11). We therefore determined whether aberrant expression of this gene might be the 


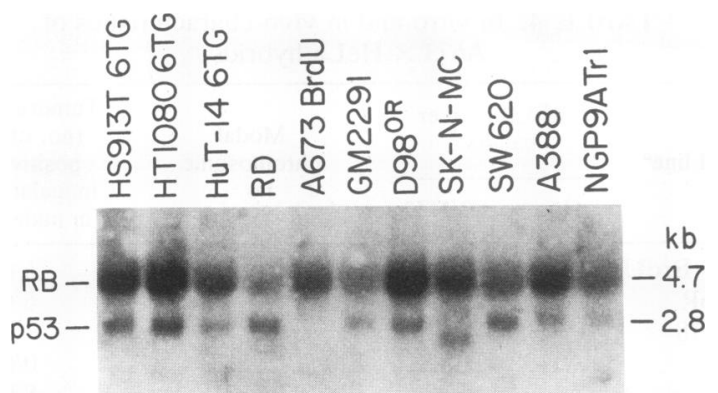

FIG. 3. Expression of $\mathrm{p} 53$ and $r b-1$ mRNAs in the parental cell lines. Expression of $\mathrm{p} 53$ and $r b-1$ mRNAs was determined by standard Northern blot analysis as previously described $(27,28)$, using a 1.8-kb BamHI fragment of p53 cDNA and a 3.8-kb EcoRI fragment of $r b-1 \mathrm{cDNA}$, respectively, as probes. The NGP9ATr1, SW620, and A388 cell lines represent a wild-type and two mutant p53 controls, respectively.

common step involved in the expression of tumorigenicity of these six cell lines by Northern and Western blotting techniques (12). All parental sarcoma cell lines displayed normalsize 4.7-kb rb-1 mRNA (Fig. 3) and apparently normal protein expression, including the active and inactive phosphorylated forms, except the SK-N-MC cell line (Fig. 4). This cell line appeared to have lost the underphosphorylated form of the protein (Fig. 4). However, in all other cases, altered expression of the RB protein did not correlate with tumorigenic expression in these cell lines.

Another potential candidate for the common tumor suppressor is the p53 gene, whose altered expression has been associated with the Li-Fraumeni syndrome $(23,27)$. We looked at p53 expression by Northern blotting analysis and immunoprecipitation of labelled proteins. By simultaneous hybridization of both the RB and p53 probes, we found normal-size p53 mRNA expressed in all cell lines except A673 BrdU and SK-N-MC. We could not detect expression

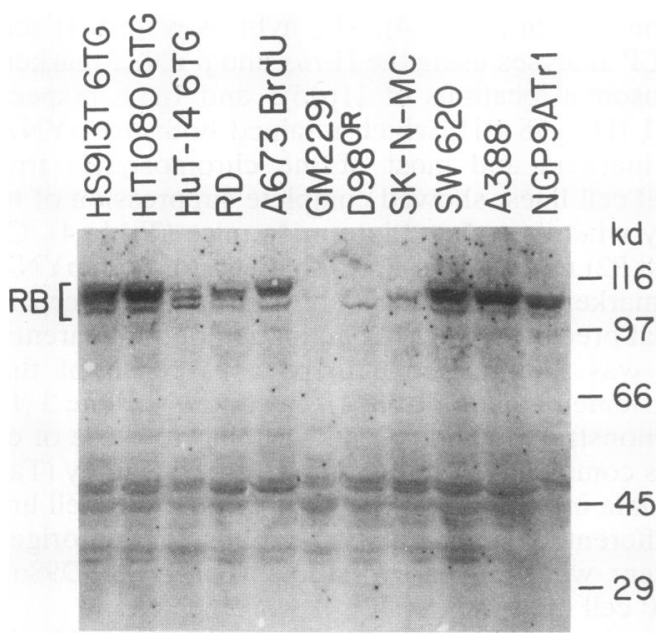

FIG. 4. Expression of the RB protein in the parental cell lines. Expression of the $r b$ - $l$-encoded protein was determined as previously described (12). The RB protein in cellular lysates from equal numbers of cells was visualized as described by Futreal and Barrett (12). The low level of protein and the lack of phosphorylated forms in the GM2291 fibroblasts probably result from their late passage number.

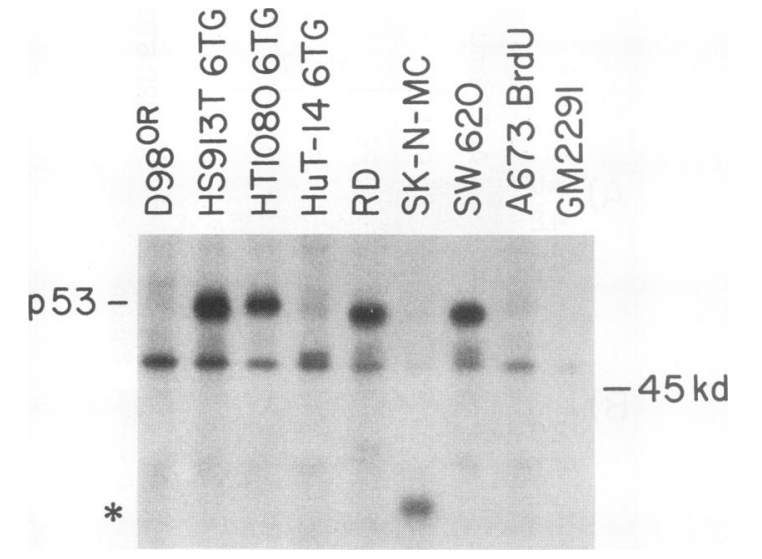

FIG. 5. Expression of the p53 protein in the parental cell lines. p53 was immunoprecipitated with Ab-1 as specified by the manufacturer (Oncogene Science). Briefly, total cellular proteins labelled with $\left[{ }^{35}\right.$ S ]methionine were incubated with monoclonal antibody $\mathrm{Ab}-1$ at $4^{\circ} \mathrm{C}$. Immune complexes were isolated by Pansorbin and separated by SDS-PAGE. Protein bands were visualized by autofluorography after treatment with $\mathrm{En}^{3} \mathrm{Hance}$ (Du Pont).

of this gene in the A673 BrdU cells, while the SK-N-MC cells had a truncated p53 mRNA (Fig. 3). We then determined the levels of p53 mRNA in the hybrids between p53 mRNA-positive cell lines and mRNA-negative A673 cells. The hybrid cells and their tumor-reconstituted derivatives expressed similar levels of the normal-size p53 mRNA (HHy7 and HHy69), while the HHy73 series displayed the truncated p53 mRNA indicative of the SK-N-MC parent (data not shown).

We next determined the levels of p53 protein in the parental and hybrid cells, as mutations account for many of the p53 abnormalities observed in human tumors. Immunoprecipitation of labelled $\mathrm{p} 53$ protein followed by SDS-PAGE showed that the HS913T, HT1080, and RD cell lines express high amounts of the p53 protein, a characteristic of mutant p53 proteins. The A673 BrdU, GM2291, and HuT14 cell lines showed trace quantities of the protein, suggesting the presence of a wild-type protein (Fig. 5). SK-N-MC expressed a truncated $\mathrm{p} 53$ protein (Fig. 5), consistent with the data from mRNA expression (Fig. 3). Therefore, the aberrant expression of the p53 gene correlated with the tumorigenic expression of these cell lines with the exception of the HuT14 cell line. However, other mechanisms might inactivate the p53 protein in this cell line (for example, MDM2 amplification).

Chromosomal analysis of PNET $\times$ fibroblast hybrid cells. As a second approach for determining the common tumor suppressor genes for soft tissue sarcomas, we examined matched sets of tumorigenic and nontumorigenic hybrid cells by use of several biochemical and molecular polymorphic markers (Table 5). Alleles of H-ras and pYNZ2 were detected by RFLP analysis. The Mfd15, Mfd47, and Mfd69 markers detected $(\mathrm{CA})_{n}$ repeat polymorphic bands by PCR amplification. The VNTR region of pYNZ22 contains polymorphic region of 70-bp repeats detectable by PCR amplification. TK activities were scored by the ability of cells to grow in HAT medium. Expression of p53 was scored by the presence of mRNA by Northern blot analysis. We excluded the HHy5 P3 cell line because its bimodal chromosome nature might confuse the interpretation of these data. Although there were random chromosome losses in HHy5 P2T, markers on chromosomes 1, 6, and 11 failed to corre- 
TABLE 5. Chromosomal analysis of PNET $\times$ fibroblast hybrids

\begin{tabular}{lcccccccc}
\hline & \multicolumn{8}{c}{ Mllele(s) present $^{b}$} \\
\cline { 2 - 8 } & Marker & & \multicolumn{7}{c}{ HHY5 } & A673 \\
\cline { 2 - 8 } & & GM2291 & P1T & P2 & P2T & P4 & P4T & BrdU \\
\cline { 2 - 8 } pYNZ2 (1p32) & 1 & $1-2$ & $1-2$ & $1-2$ & 2 & $1-2$ & $1-2$ & 2 \\
Mfd47 (6) & 1 & $1-2$ & $1-2$ & $1-2$ & 2 & $1-2$ & $1-2$ & 2 \\
HRAS1 (11p15) & 1 & $1-2$ & $1-2$ & $1-2$ & 2 & $1-2$ & $1-2$ & 2 \\
Mfd69 (11q23) & 1 & $1-2$ & $1-2$ & $1-2$ & 2 & $1-2$ & $1-2$ & 2 \\
pYNZ22 (17p13.3) & 1 & $1-2$ & 2 & 2 & 2 & $1-2$ & 2 & 2 \\
p53 (17p13.1) & + & + & - & - & - & + & - & - \\
Mfd15 (17q11-12) & 1 & $1-2$ & 2 & $1-2$ & 2 & $1-2$ & $1-2$ & 2 \\
TK (17q23-25) & + & + & + & + & + & + & + & - \\
\hline
\end{tabular}

${ }^{a}$ Numbers in parentheses represent chromosome location.

${ }^{b}$ Numbers represent the presence of GM2291 (1) or A673 BrdU (2) alleles. Presence of the p53 gene was determined by its expression on Northern blots. TK activity was measured by the ability of the cells to grow in HAT selective medium. $\mathrm{T}$ indicates derivation from a tumor formed by the preceding cell line.

late with appearance of tumorigenic segregants (Table 5). HHy5 P1T and HHy5 P2T had both lost the Mfd15 marker, located on chromosome 17q11-12, when they became tumorigenic (Fig. 6C; Table 5). However, HHy5 P4T still retained this marker, indicating that the Mfd15 was not close to the putative tumor suppressor gene. Only loss of the fibroblastderived p53 and pYNZ22 markers correlated with reexpression of tumorigenicity in the HHy5 P1 and HHy5 P4 cell lines (Fig. 6A and B; Table 5). Thus, this second line of evidence mapped the common tumor suppressor gene to the short arm of chromosome 17, consistent with location of the p53 gene.

Transfer of chromosome 17 to $\mathrm{A673}$ BrdU cells by microcell hybridization. To test the ability of the p53 gene to modulate tumorigenicity in this system, we tried to introduce the wild-type gene by transfection using the Lipofectin reagent. As reported in other studies $(1,10)$, we could not isolate viable colonies of cells after introduction of the wild-type p53 gene into the p53-deficient A673 BrdU cell line.

To circumvent problems related to overexpression of the wild-type $\mathrm{p} 53$ protein in cells after transfection, we decided to transfer a normal human chromosome 17 into the A673 BrdU cells by microcell hybridization. Expression of the p53 gene, which resides on this chromosome, should operate in a normal fashion as a result of the presence of all normal regulatory elements. By introducing a chromosome 17 from a normal human cell into the A673 BrdU cells, we could then functionally assay for the presence of a tumor suppressor activity. We could obtain only four independent clones from two experiments, suggesting a growth-inhibitory activity on this chromosome. These microcell hybrids remained tumorigenic when inoculated into nude mice, indicating the absence of a tumor suppressor gene for the A673 BrdU cell line (data not shown). We then examined several markers on the chromosome 17 to determine whether the entire chromosome 17 was retained in the microcell hybrids. All of the microcell hybrids contained the dinucleotide repeat polymorphic marker Mfd15, located on 17q11-12, from both A673 cells and introduced chromosome 17 . These cells could also proliferate in HAT selective medium, indicating the retention of another long-arm gene, $t k$. However, they showed only the A673 allele for the marker pYNZ22, located on 17p13.3, and did not express p53 mRNA (17p13.1) (data not shown). Thus, the molecular marker analysis on the microcell hybrids indicated a strong selective pressure
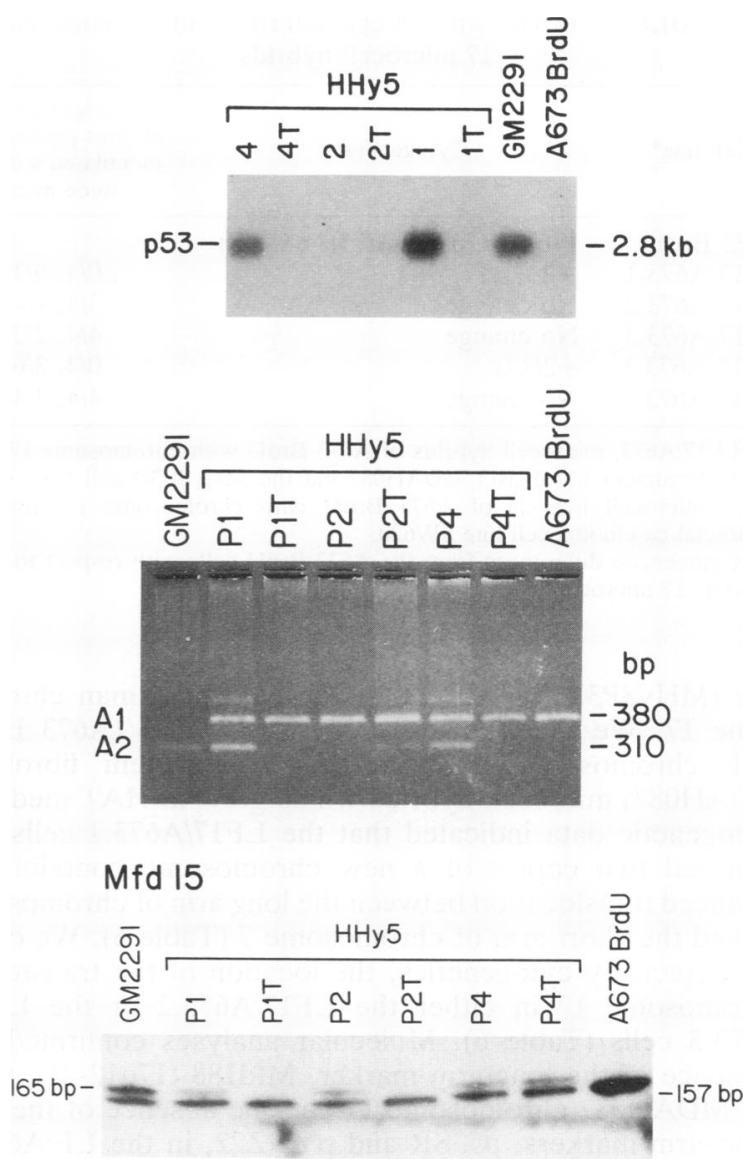

FIG. 6. Molecular analysis of PNET $\times$ fibroblast hybrids. (A) Expression of p53 mRNA in the parental and hybrid cell lines, determined by Northern blotting as described in Materials and Methods. (B) Amplification of the pYNZ22 VNTR region, using PCR as described by Horn et al. (18). PCR products were fractionated on a $2 \%$ agarose gel and visualized by ethidium bromide staining. (C) Detection of the Mfd15 dinucleotide (CA) $)_{n}$ repeat polymorphic region by PCR as described by Weber and May (43), using ${ }^{32} \mathrm{P}$-end-labelled primers. PCR products were separated by DNA sequencing gel and visualized by autoradiography.

against the retention of the short arm of the normal chromosome 17 , similar to findings of Goyette et al. (15).

The most likely cause of this selective pressure comes from the growth-suppressive effects of the wild-type p53 on the short arm. Therefore, we designed experiments to eliminate the growth-suppressive effects of the wild-type p53 to better search for a functional tumor suppressor gene on chromosome 17. We took advantage of the presence of the $t k$ gene on chromosome 17 to transfer chromosome $17 \mathrm{~s}$ with p53 mutations from a colon carcinoma cell line, SW620, or a Li-Fraumeni fibroblast line, MDAH087, into the $\mathrm{TK}^{-}$ A673 BrdU cells. The SW620 cell line contains one mutant p53 gene with two mutations, codon $273^{\text {Arg-His }}$ and codon $309^{\text {Pro-Ser }}$ (7). The MDAH087 fibroblasts contain a homozygous mutation at codon $248^{\mathrm{Arg}-\mathrm{Tr} p}(22)$. The microcell hybrids between A673 BrdU and donor cell line SW620 or MHy8P3B were selected for TK activity (located on 17q2325), using HAT medium.

Because of poor micronucleation after colcemid treatment, we first fused the MDAH087 fibroblasts to $\mathrm{L} \mathrm{TK}^{-}$) mouse fibrosarcoma cells to generate a microcell donor cell 
TABLE 6. In vivo growth characteristics of chromosome 17 microcell hybrids

\begin{tabular}{llc}
\hline \multicolumn{1}{c}{ Cell line ${ }^{a}$} & \multicolumn{1}{c}{ Cytogenetics $^{b}$} & $\begin{array}{c}\text { Tumorigenicity (no. } \\
\text { of sites positive/no. } \\
\text { inoculated s.c. into } \\
\text { nude mice) }\end{array}$ \\
\hline A673 BrdU & $17 \mathrm{q}-, 17 \mathrm{p}+, \mathrm{t}(2 ; 17), \mathrm{t}(17 ; 18)$ & \\
LF17/A673.1 & $+2 \mathrm{t}(7 ; 17)$ & $0 / 4,0 / 3$ \\
LF17/A673.2 & No change & $3 / 4,4 / 4$ \\
LF17/A673.3 & No change & $4 / 4,2 / 2$ \\
CC17/A673.1 & $+2(17)$ & $0 / 4,3 / 6$ \\
CC17/A673.2 & No change & $4 / 4,4 / 4$ \\
\hline
\end{tabular}

${ }^{a}$ LF17/A673, microcell hybrids of A673 BrdU with chromosome 17 from the Li-Fraumeni fibroblasts MDAH087 via the MHy8P3B cell line; CC17/ A673, microcell hybrids of $\mathrm{A} 673 \mathrm{BrdU}$ with chromosome 17 from the colorectal carcinoma cell line SW620.

${ }^{b}$ Cytogenetic differences from the A673 BrdU cells with respect to chromosome 17 microcell hybrids by G-banding analyses.

line (MHy8P3B) which contained a single human chromosome 17. We then isolated three LF17/A673 (A673 BrdU with chromosome 17 from the Li-Fraumeni fibroblast MDAH087) microcell hybrids which grew in HAT medium. Cytogenetic data indicated that the LF17/A673.1 cells had acquired two copies of a new chromosome containing a balanced translocation between the long arm of chromosome 17 and the short arm of chromosome 7 (Table 6). We could not detect, by cytogenetics, the location of the transferred chromosome 17 in either the LF17/A673.2 or the LF17/ A673.3 cells (Table 6). Molecular analyses confirmed the presence of the long-arm marker, Mfd188 (17q12-21), from the MDAH087 chromosome 17 and the absence of the two short-arm markers, p53SR and pYNZ22, in the LF/A673.1 cell line (Table 7). The LF/A673.2 cell line also contained the Mfd188 marker, while only the LF17/A673.3 cells acquired the p53SR marker from the MDAH087 chromosome 17 (Table 7). Both the LF17/A673.2 and LF17/A673.3 cell lines remained highly tumorigenic when inoculated into nude mice, whereas the LF17/A673.1 became nontumorigenic (Table 6). Northern blot analysis also demonstrated a lack of detectable p53 mRNA in the LF17/A673.1 cell line (data not shown). Thus, the addition of genetic material from the fibroblast-derived chromosome 17 caused suppression of tumorigenicity in this cell line.

In the case of the SW620 cells, we directly transferred chromosome 17 from the cell line in the same way as for the other chromosome donor cell lines. We isolated two CC17/ A673 (A673 BrdU with a chromosome 17 from the SW620 colon carcinoma cell line) microcell hybrids. Both molecular and cytogenetic analyses indicated that the CC17/A673.2 cells did not contain an intact chromosome 17 from the SW620 cell line (Tables 6 and 7). The CC17/A673.1 cells, on the other hand, had genetic markers from both A673 BrdU and SW620 for all three markers examined (Mfd15, Mfd188, and p53SR) (Table 7). Cytogenetic data also revealed that the CC17/A673.1 cells contained two additional copies of intact chromosome 17s compared with A673 BrdU cells (Table 6). These hybrid cells failed to form tumors upon inoculation into nude mice, demonstrating tumor suppressor function for the A673 BrdU cells on the transferred chromosome 17 (Table 6). Reverse transcription-PCR analysis of the p53 mRNA expressed in the CC17/A673.1 cell line confirmed the presence of the two mutations present in the SW620 donor cell line and the absence of any wild-type p53 mRNA (data not shown).

\section{DISCUSSION}

In this report, we have demonstrated that six human soft tissue sarcoma cell lines belong to the same tumorigenicity complementation group, suggesting defects in a common tumor suppressor gene. At present, molecular studies have identified at least eleven tumor suppressor genes for human tumors. The most likely candidate in this group for the common tumor suppressor gene for soft tissue sarcomas was either RB or p53. Both of these genes show aberrant expression in soft tissue sarcomas in vivo. This report demonstrated that nearly all soft tissue sarcoma lines displayed normal RB protein expression by Western blot analysis. While the possibility remains that these proteins contain undetected abnormalities, these data would appear to eliminate the RB gene as the common defect in the control of tumorigenic expression. However, our studies did demonstrate abnormal p53 expression in five of six soft tissue sarcoma cell lines, as judged from lack of expression (A673 BrdU), truncated protein (SK-N-MC), or mutant protein. Furthermore, loss of the short arm of chromosome 17, the site of the p53 gene, correlated with reexpression of tumorigenicity in tumorigenic segregants of $\mathrm{A} 673 \mathrm{BrdU} \times$ normal fibroblast hybrids.

However, several lines of evidence suggest that a second gene on chromosome 17 actually modulates tumorigenicity in these cells. We have previously shown that hybrids between HeLa and HT1080 cells or OHS-50 osteosarcoma cells are suppressed for tumorigenic potential $(28,46)$. The HT1080 and OHS-50 cell lines have either mutant or deleted

TABLE 7. Molecular analyses of chromosome 17 microcell hybrids

\begin{tabular}{|c|c|c|c|c|c|c|}
\hline \multirow{2}{*}{ Cell line ${ }^{a}$} & \multicolumn{6}{|c|}{ Presence or absence of marker from the introduced chromosome 17} \\
\hline & $\mathrm{q}^{23-25, b} \mathrm{TK}^{c}$ & q12-21, Mfd188 & q11-12, Mfd15 & $\mathrm{p} 13.1, \mathrm{p} 53^{d}$ & p13.1, ${\mathrm{p} 53 S R^{e}}^{e}$ & p13.3, pYNZ22 \\
\hline LF17/A673.1 & + & + & $\mathbf{N P}$ & - & - & - \\
\hline LF17/A673.2 & + & + & NI & - & - & - \\
\hline LF17/A673.3 & + & - & NI & - & + & - \\
\hline CC17/A673.1 & + & + & + & + & + & NI \\
\hline CC17/A673.2 & + & - & - & - & - & NI \\
\hline
\end{tabular}

${ }^{a}$ LF17/A673, microcell hybrids of A673 BrdU with chromosome 17 from the Li-Fraumeni fibroblasts MDAH087 via the MHy8P3B cell line; CC17/A673, microcell hybrids of A673 BrdU with chromosome 17 from the colorectal carcinoma cell line SW620.

${ }^{b}$ Locations of the marker on chromosome 17.

c Scored by ability to grow in HAT medium.

d Measured by Northern blot analysis.

e The p53SR marker recognizes an (AAAAT) $)_{n}$ simple repeat in the first intron of the p53 gene (13).

$f \mathrm{NI}$, not informative. 
p53 genes, while the presence of the human papillomavirus E6 protein causes the rapid degradation of the wild-type p53 gene in HeLa cells (32). Therefore, suppression of tumorigenicity occurs in the absence of normal p53 protein. The HT1080 cell line falls into the same complementation group as the A673 BrdU cell line, suggesting that a gene other than the p53 gene modulates tumorigenicity in these cells. In this report, whole cell hybrids between A673 BrdU and D98oR, a HeLa cell derivative, were also suppressed for tumorigenicity. The HeLa $\times$ A673 hybrids continue to express the human papillomavirus E6 protein (7). Thus, the A673 $\times$ HeLa hybrids remain nontumorigenic in the absence of functional p53 protein.

More directly, two different microcell hybrids of the A673 BrdU cell line containing chromosome 17s from cells with mutant p53 genes failed to form tumors in nude mice. In one case, CC17/A673.1, the suppression occurred in presence of mutant p53 expression, while the nontumorigenic LF/A673.1 cell line expressed no p53 mRNA. These results formally eliminate the $\mathrm{p} 53$ gene as the sole arbitrator of tumorigenicity in this system. They also map a functional tumor suppressor gene to a location between 17qter and the p53 gene. Finally, they present a potent reminder against equating monochromosome transfer experiments with gene transfection studies.

Human chromosome 17 contains other tumor suppressor genes which could control tumorigenic expression in these cell lines. Molecular and cytogenetic analyses of breast carcinomas and brain tumors also implicated a tumor suppressor gene on the short arm of chromosome 17 other than p53 $(6,16)$. Molecular epidemiological studies have mapped a susceptibility gene for early onset of breast cancer to the long arm of chromosome 17 (17). A particularly attractive candidate for a tumor suppressor gene for PNETs is the neurofibromatosis type 1 gene, which maps to the long arm of this chromosome $(38,39)$. Recent evidence has shown that neuroblastomas, a tumor type closely related to PNET, display abnormalities in this gene (19). We are currently localizing the site of the operative tumor suppressor gene by transferring smaller fragments of chromosome 17 into PNET cell lines. We are also examining neurofibromatosis type 1 gene expression in the tumorigenic and nontumorigenic parental cells and microcell hybrids.

A recent study by Chen et al. (7) suggested that the p53 gene acts as a tumor suppressor gene for the A673 cell line without inhibiting cell growth. One possibility for the differences between these two studies could be the use of a mixed population by the former, compared with the clonally derived A673 BrdU cell line used in this study. However, the data presented by Chen et al. actually support the conclusions reached by our study. Two of the three p53 infectants showed an increased doubling time in culture. Furthermore, all clones eventually formed tumors in nude mice, suggesting that the increased latency period in animals arose from the slower growth rate in culture. In our study either transfer of a normal chromosome 17 containing the p53 gene or transfection of the p53 gene alone into the A673 BrdU cell line caused strong inhibition of cellular proliferation. These data suggest a role for the p53 gene in the control of cell growth.

Two of the major problems facing oncologists today are tumor classification and prognostic indicators. The finding in this study that soft tissue sarcomas share a common defective tumor suppressor gene may provide a reliable marker for tumor progression upon its isolation and characterization. Furthermore, if expression of this gene is developmentally regulated, it may be useful for classifying different tumor types. This study again stresses the importance of functional analyses for identifying operative tumor suppressor genes for human malignancies.

\section{ACKNOWLEDGMENTS}

We thank H. Sheldon Earp and Thea Tlsty for helpful discussions. We thank Y. Nakamura for the pYNZ2 probe, Yuen-Kai Fung for the RB probe, Bert Vogelstein for the p53 probes and expression vectors, and Edison Liu for the pYNZ22 primers. We also thank Paul Arnstein for testing the tumorigenicity of the A673 BrdU $\times$ GM2291 hybrid cell lines.

This work was supported in part by PHS grant CA44470 (B.E.W.).

\section{REFERENCES}

1. Baker, S. J., S. Markowitz, E. R. Fearon, J. K. V. Willson, and B. Vogelstein. 1990. Suppression of human colorectal carcinoma cell growth by wild-type p53. Science 249:912-915.

2. Benedict, W. F., B. E. Weissman, C. Mark, and E. J. Stanbridge. 1984. Tumorigenicity of human HT1080 fibrosarcoma $\times$ normal human fibroblasts: chromosome dosage dependency. Cancer Res. 44:3471-3479.

3. Biedler, J. L., L. Helson, and B. A. Spengler. 1973. Morphology and growth, tumorigenicity, and cytogenetics of human neuroblastoma cell lines in continuous culture. Cancer Res. 33:26432652.

4. Bishop, J. M. 1987. The molecular genetics of cancer. Science 235:305-311.

5. Brodeur, G. M., G. L. Sekhon, and M. N. Goldstein. 1977. Chromosomal aberrations in human neuroblastomas. Cancer (Philadelphia) 40:2256-2263.

6. Chen, L.-C., A. Neubauer, W. Kurisu, F. M. Waldman, B.-M. Ljung, W. Goodson III, E. S. Goldman, D. Moore II, M. Balazs, E. Liu, B. H. Mayall, and H. S. Smith. 1991. Loss of heterozygosity on the short arm of chromosome 17 is associated with high proliferative capacity and DNA aneuploidy in primary breast cancer. Proc. Natl. Acad. Sci. USA 88:3847-3851.

7. Chen, P., and B. E. Weissman. Unpublished observations.

8. Chen, Y., P.-L. Chen, N. Arnaiz, D. Goodrich, and W.-H. Lee. 1991. Expression of wild-type p53 in human A673 cells suppresses tumorigenicity but not growth rate. Oncogene 6:17991805.

9. Comings, D. E. 1973. A general theory of carcinogenesis. Proc. Natl. Acad. Sci. USA 70:3324-3328.

10. Dillar, L., J. Kassel, C. E. Nelson, M. A. Gryka, G. Litwak, M. Gebhardt, B. Bressac, M. Ozturk, S. J. Baker, B. Vogelstein, and S. H. Friend. 1990. p53 functions as a cell cycle control protein in osteosarcomas. Mol. Cell. Biol. 10:5772-5781.

11. Friend, S. H., R. Bernards, S. Rogeli, R. A. Weinberg, J. M. Rapaport, D. A. Albert, and T. P. Dryja. 1986. A human DNA segment with properties of the gene that predisposes to retinoblastoma and osteosarcoma. Nature (London) 323:643-646.

12. Futreal, P. A., and J. C. Barrett. 1991. Failure of senescent cells to phosphorylate the RB protein. Oncogene 6:1109-1113.

13. Futreal, P. A., J. C. Barrett, and R. W. Wiseman. 1991. An Alu polymorphism intragenic to the TP53 gene. Nucleic Acids Res. 19:6977.

14. Giard, D. J., S. A. Aaronson, G. J. Todaro, P. Arnstein, J. H. Kersey, H. Dosik, and W. P. Parks. 1974. In vitro cultivation of human tumors: establishment of cell lines derived from a series of solid tumors. J. Natl. Cancer Inst. 51:1417-1423.

15. Goyette, M. C., K. Cho, C. L. Fasching, D. B. Levy, K. W. Kinzler, C. Paraskeva, B. Vogelstein, and E. J. Stanbridge. 1992. Progression of colorectal cancer is associated with multiple tumor suppressor gene defects but inhibition of tumorigenicity is accomplished by correction of any single defect via chromosome transfer. Mol. Cell. Biol. 12:1387-1395.

16. Griffin, C. A., A. L. Hawkins, R. J. Packer, L. B. Rorke, and B. S. Emmanuel. 1988. Chromosome abnormalities in pediatric brain tumors. Cancer Res. 48:175-180.

17. Hall, J. M., M. K. Lee, B. Newman, J. E. Morrow, L. A. Anderson, B. Huey, and M.-C. King. 1991. Linkage of early- 
onset familial breast cancer to chromosome 17q21. Science 250:1684-1690.

18. Horn, G. H., B. Richards, and K. W. Klinger. 1989. Amplification of a highly polymorphic VNTR segment by the polymerase chain reaction. Nucleic Acids Res. 17:2140.

19. Johnson, M. R., T. A. Look, J. E. DeClue, M. B. Valentine, and D. R. Lowy. 1993. Inactivation of the NF1 gene in human melanoma and neuroblastoma cell lines without impaired regulation of GTP-Ras. Proc. Natl. Acad. Sci. USA 90:5539-5543.

20. Kakunaga, T. 1978. Neoplastic transformation of human diploid fibroblasts by chemical carcinogens. Proc. Natl. Acad. Sci. USA 75:1334-1338.

21. Knudson, A. G. 1971. Mutation and cancer: statistical study of retinoblastoma. Proc. Natl. Acad. Sci. USA 68:820-823.

22. Livingstone, L. R., A. White, J. Sprouse, T. Jacks, and T. D. Tlsty. 1992. Altered cell cycle arrest and gene amplification potential accompany loss of wild-type p53. Cell 70:1-20.

23. Malkin, D., F. P. Li, L. C. Strong, J. F. Fraumeni, Jr., C. E. Nelson, D. H. Kim, J. Kassel, M. A. Gryka, F. Z. Bischoff, M. A. Tainsky, and S. H. Friend. 1990. Germ line p53 mutations in a familial syndrome of breast cancer, sarcomas and other neoplasms. Science 250:1233-1238.

24. McAllister, R. M., J. Melnyk, J. Z. Finklestein, E. C. Adams, and M. B. Gardner. 1969. Cultivation in vitro of cells derived from a human rhabdomyosarcoma. Cancer (Philadelphia) 24: 520-526.

25. McCormick, J. J., D. Yang, V. M. Maher, R. A. Farber, W. Neuman, W. D. Peterson, Jr., and M. S. Pollack. 1988. The HuT series of 'carcinogen-transformed' human fibroblast cell lines are derived from the human fibrosarcoma cell line 8387. Carcinogenesis 9:2073-2079.

26. Nelson-Rees, W. A., V. M. Zhdnov, P. K. Hawthorne, and R. R. Flandermeyer. 1974. HeLa-like marker chromosome and type-A variant glucose-6-phosphate dehydrogenase isoenzyme in human cell cultures producing Mason-Pfizer monkey virus-like particles. J. Natl. Cancer Inst. 53:751-757.

27. Nigro, J. M., S. J. Baker, A. C. Preisinger, J. M. Jessup, R. Hostetter, K. Cleary, S. H. Bigner, N. Dividson, S. Baylin, P. Devilee, T. Glover, F. S. Collins, A. Weston, R. Modali, C. C. Harris, and B. Vogelstein. 1989. Mutations in the p53 gene occur in diverse human tumor types. Nature (London) 342:705-708.

28. Pasquale, S. R., G. R. Jones, C.-J. Doersen, and B. E. Weissman. 1988. Tumorigenicity and oncogene expression in pediatric cancers. Cancer Res. 48:2715-2719.

29. Rasheed, S., W. A. Nelson-Rees, E. M. Tooth, P. Arnstein, and M. B. Gardner. 1974. Characterization of a newly derived human sarcoma cell line (HT-1080). Cancer (Philadelphia) 33: $1027-1033$.

30. Saxon, P. J., E. S. Srivatsan, G. V. Leipzig, J. H. Sameshima, and E. J. Stanbridge. 1985. Selective transfer of individual human chromosomes to recipient cells. Mol. Cell. Biol. 5:140 146.

31. Saxon, P. J., E. S. Srivatsan, and E. J. Stanbridge. 1986. Introduction of human chromosome 11 via microcell transfer controls tumorigenic expression of HeLa cells. EMBO J. 5:3461-3466.

32. Scheffner, M., B. A. Werness, J. M. Huibregtse, A. J. Levine, and P. M. Howley. 1990. The E6 oncoprotein encoded by human papillomavirus type 16 and 18 promotes degradation of p53. Cell 63:1129-1136.

33. Scrable, H., W. Cavenee, F. Ghavimi, M. Lovell, K. Morgan, and C. Sapienza. 1989. A model for embryonal rhabdomyosarcoma tumorigenesis that involves genome imprinting. Proc. Natl. Acad. Sci. USA 86:7480-7484.

34. Srivatsan, E. S., W. F. Benedict, and E. J. Stanbridge. 1986. Implication of chromosome 11 in the suppression of neoplastic expression in human cell hybrids. Cancer Res. 46:6174-6179.

35. Stanbridge, E. J. 1976. Suppression of malignancy in human cells. Nature (London) 260:17-20.

36. Stanbridge, E. J. 1981. Mycoplasma detection-an obligation to scientific accuracy. Isr. J. Med. Sci. 17:563-56.

37. Stanbridge, E. J., R. R. Flandermeyer, D. W. Daniels, and W. A. Nelson-Rees. 1981. Specific chromosome loss associated with the expression of tumorigenicity in human cell hybrids. Somatic Cell Genet. 7:699-712.

38. Viskochil, D., A. M. Buchberg, G. Xu, R. M. Cawthon, J. Stevens, R. K. Wolfi, M. Culver, J. C. Carey, N. G. Copeland, N. A. Jenkins, R. White, and P. O'Connell. 1990. Deletions and a translocation interrupt a cloned gene at the neurofibromatosis type 1 locus. Cell 62:187-92.

39. Wallace, M. R., D. A. Marchuk, L. B. Andersen, R. Letcher, H. M. Odeh, A. M. Saulino, J. W. Fountain, A. Brereton, J. Nicholson, A. L. Mitchell, B. H. Brownstein, and F. S. Collins. 1990. Type 1 neurofibromatosis gene: identification of a large transcript disrupted in three NF1 patients. Science 249:181-86.

40. Weber, J. L., A. E. Kwitek, and P. E. May. 1990. Dinucleotide repeat polymorphisms at the D6S87 locus. Nucleic Acids Res. 18:4636.

41. Weber, J. L., A. E. Kwitek, and P. E. May. 1990. Dinucleotide repeat polymorphisms at the D11S419 and CD3D loci. Nucleic Acids Res. 18:4036.

42. Weber, J. L., A. E. Kwitek, P. E. May, M. R. Wallace, F. C. Collins, and D. H. Ledbetter. 1990. Dinucleotide repeat polymorphisms at the D17S250 and D17S261 loci. Nucleic Acids Res. 18:4640.

43. Weber, J. L., and P. E. May. 1989. Abundant class of human DNA polymorphisms which can be typed using the polymerase chain reaction. Am. J. Hum. Genet. 44:388-396.

44. Weissman, B. E. 1990 . Genetic behavior of tumorigenicity in human cancer. Cancer Surv. 9:475-485.

45. Weissman, B. E., and E. J. Stanbridge. 1980. Characterization of ouabain-resistant, hypoxanthine guanine phosphoribosyl transferase-deficient human cells and their usefulness as a general method for the production of human cell hybrids. Cytogenet. Cell Genet. 28:227-239.

46. Weissman, B. E., and E. J. Stanbridge. 1983. Complementation of the tumorigenic phenotype in human cell hybrids. J. Natl. Cancer Inst. 70:667-672. 